\title{
Eosinophilic enterocolitis diagnosed by means of technetium-99m albumin scintigraphy and treated with budesonide (CIR)
}

\author{
M G V M Russel, R N M Zeijen, R-J M Brummer, A P de Bruine, \\ M J P G van Kroonenburgh, R W Stockbrügger
}

\begin{abstract}
A patient with a 15 year history of diarrhoea of unknown origin is described. Scintigraphy with technetium-99m labelled albumin suggested albumin loss at the terminal ileum and caecum; subsequent colonoscopic biopsies of these macroscopically normal looking areas showed abundant infiltration with eosinophils. A diagnosis of eosinophilic enterocolitis was made. Treatment with prednisolone had good results, but had to be stopped because of severe side effects. Oral cromoglycate and mesalazine were not effective. Budesonide (CIR), a new topically active corticosteroid with very little systemic effects, was at least as effective as prednisolone without producing side effects.
\end{abstract}

(Gut 1994; 35: 1490-1492)

Chronic diarrhoea can be a diagnostic challenge. We describe a patient with disabling, protein losing diarrhoea, in whom the diagnosis was established 15 years after the start of symptoms, after localising the site of protein loss.

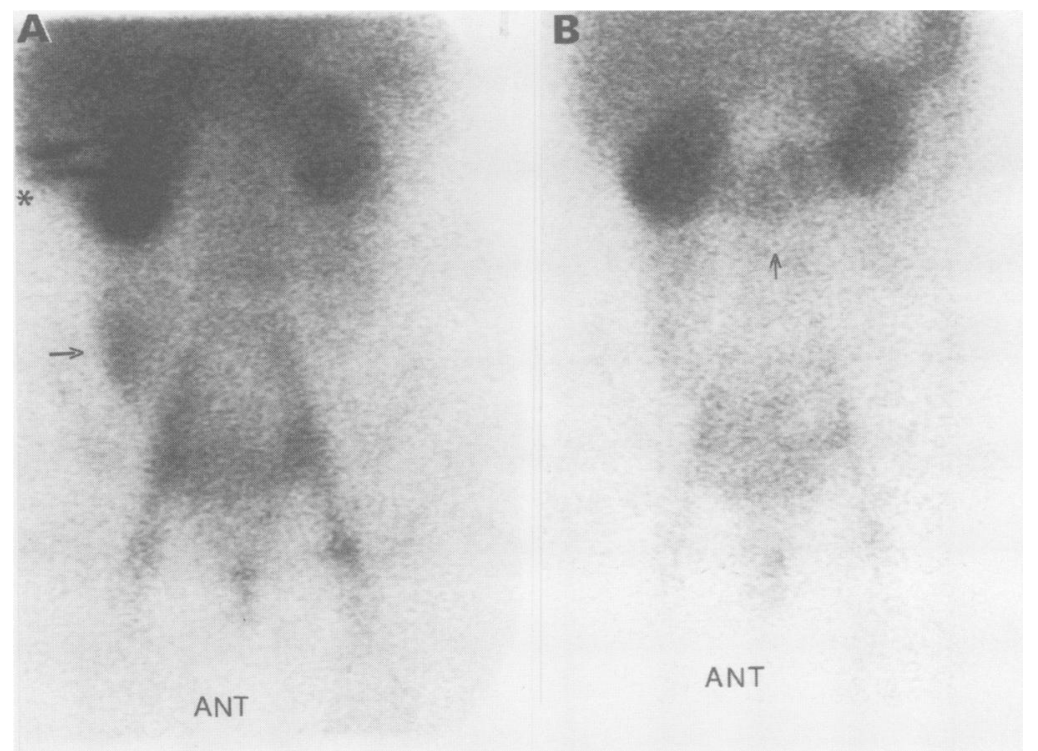

Figure 1: ${ }^{99 \mathrm{~m}}$ Tc labelled human albumin scintigraphy of the patient showing clear visualisation of tracer accumulation (arrow) in the region of the terminal ileum and caecum $(A)$ at six hours and $(B)$ in the region of the colon ascendens at 24 hours after injection $\left({ }^{\star}=\right.$ technical artefact $)$.

\section{Case report}

A 42 year old woman was referred with a 13 year history of watery diarrhoea with a frequency ranging from five to 15 times a day. She also experienced crampy abdominal pains related to defecation. There was no discharge of blood or mucus. A presumptive diagnosis of irritable bowel syndrome had been made in the past. She had a good appetite, there was no history of food intolerance, and her body weight had been stable during the years. There was a history of urticaria, and she was allergic to a necklace made out of nickel. She smoked 15 cigarettes a day, and denied taking any drugs or alcohol.

On physical examination the patient seemed well. The body weight was $64 \mathrm{~kg}$, height $1.59 \mathrm{~m}$, and no abnormal findings were detected. The haematological and blood chemical findings were normal, including serum concentrations of thyroid stimulating hormone. No traces of laxatives were found in the urine and faeces. Cultures and microscopy of the faeces were negative on several occasions. A 72 hour stool collection showed a mean weight of $450 \mathrm{~g} /$ day and a fat excretion of 7 g/day. The faecal osmotic gap was 50 mosmol/1. Small bowel enteroclysis and initial endoscopic investigations of the upper gastrointestinal tract and the colon were normal, as were duodenal and rectal biopsies. The $\mathrm{pH}$ of the gastric juice was 1.5 at endoscopy.

Because of a weight loss of two $\mathrm{kg}$ and a slight decrease of the serum albumin in time (40 to $36 \mathrm{~g} / \mathrm{l}$ ), a chromium ${ }^{51}$ labelled chloride test was performed, which showed a faecal protein loss of $1.4 \mathrm{~g} /$ day (normal: $<0.5 \mathrm{~g} /$ day). To find out if this protein loss could be further localised we performed a technetium-99m $\left.{ }^{99 \mathrm{~m}} \mathrm{Tc}\right)$ labelled albumin scintigraphy. ${ }^{1}$ Multiple serial anterior images of the abdomen were obtained until 24 hours after the injection of $15 \mathrm{mCi}{ }^{99 m} \mathrm{Tc}$ human serum albumin. Abnormal images were first seen six hours after injection with clear visualisation of tracer accumulation in the region of the terminal ileum and caecum (Fig 1A) and subsequently in the region of the colon ascendens 24 hours after injection (Fig 1B). To exclude a false positive result caused by free ${ }^{99 \mathrm{~m}} \mathrm{Tc}$, a second study was done with $3 \mathrm{mCi}{ }^{99 m} \mathrm{Tc}$ pertechnetate intravenously, which did not show accumulation of ${ }^{99 \mathrm{~m}} \mathrm{Tc}$ pertechnetate in this area (Fig 2). 
Subsequent biopsy specimens of these endoscopically normal looking areas (which had not been biopsied at the first colonoscopy), showed non-specific inflammation of the lamina propria with abundant eosinophils (Fig 3) and IgE containing plasma cells (Fig 4). A diagnosis of eosinophilic enterocolitis was made and oral corticosteroid treatment $(40 \mathrm{mg}$ prednisolone/day) was started. Stools became well formed and, within two weeks, the frequency decreased to twice daily. Severe side effects of this treatment, however, such as moonface and mental alterations, were not tolerated by the patient. When the corticosteroid dose was decreased below $30 \mathrm{mg} /$ day, the bowel symptoms returned. Alternative therapeutic

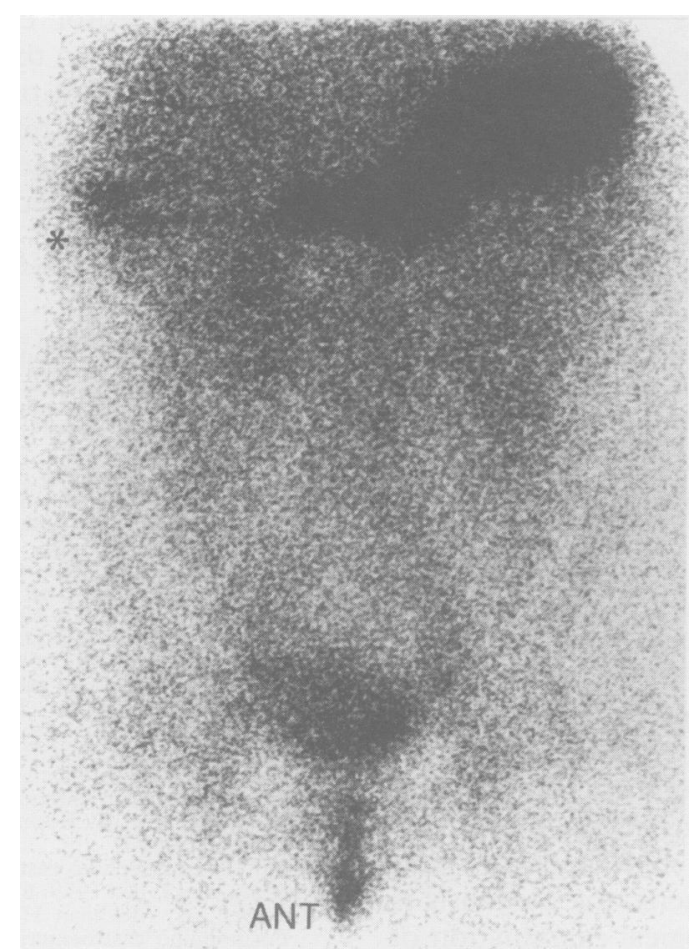

Figure 2: A control scintigram was performed with ${ }^{99 \mathrm{~m}} T c$ pertechnetate from the same abdominal area six hours after injection.

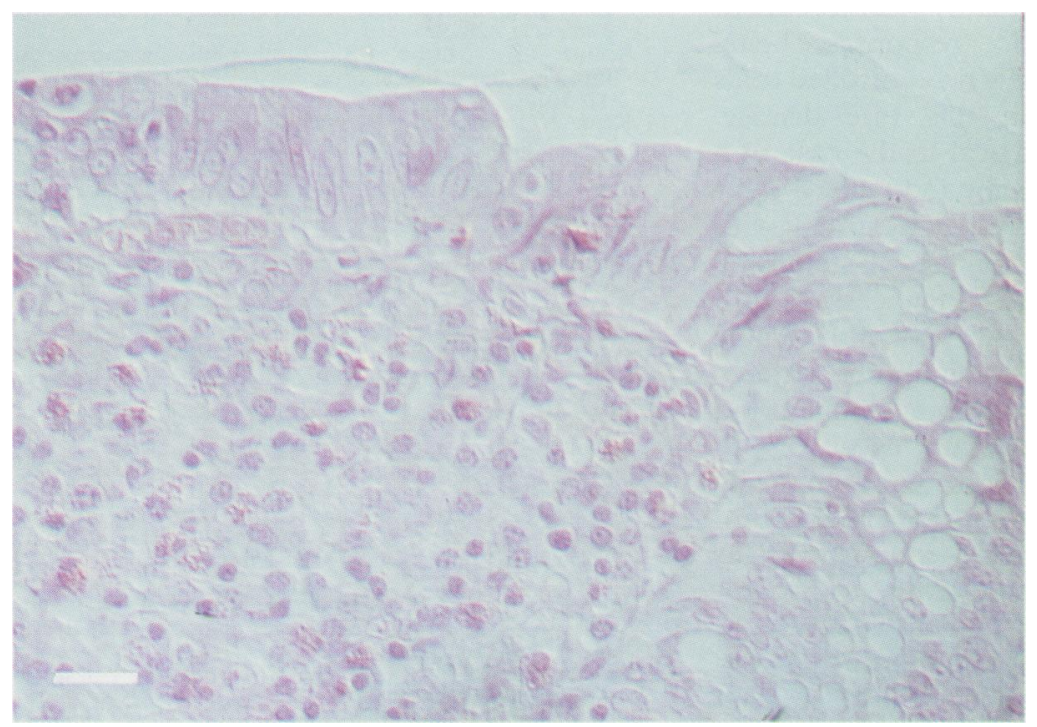

Figure 3: Endoscopic biopsy specimen of the caecum with non-specific inflammation of the lamina propria with abundant eosinophils, haematoxylin and eosin staining (bar=approximately 3 micrometer). approaches with sodium cromoglycate and mesalazine had no effect.

At that time we tried budesonide CIR (controlled ileal release), a topically active corticosteroid in a slow release form with $90 \%$ first pass hepatic metabolism, in a dose of 9 $\mathrm{mg} /$ day orally, which is topically equivalent to about $30 \mathrm{mg}$ prednisolone. ${ }^{2}$ The patient responded within two weeks and had one or two formed stools per day. During a follow up of five months she did not develop any signs of hypercortisolism and remained clinically well while receiving a maintenance dose of $6-9 \mathrm{mg}$ budesonide CIR per day. The serum albumin concentration returned to the normal range at $40 \mathrm{~g} / \mathrm{l}$ and repeated imaging with ${ }^{99 \mathrm{~m}} \mathrm{Tc}$ human serum albumin showed remarkable reduction of radioactivity in the region of the terminal ileum and caecum. Repeated histological examination of the caecum was performed five months after treatment, which showed less severe inflammation with still a predominance of eosinophils.

\section{Discussion}

Eosinophilic enterocolitis is a rare disease. Since its first description by Kaijser in 1937 less than 200 cases have been reported. ${ }^{3}$ The disease can be defined as the presence of abdominal complaints in connection with abnormal eosinophilic infiltration in one or more areas of the gastrointestinal tract. Although blood eosinophilia is often mentioned in published reports it is not a universal finding, occurring in $20-90 \%$ of cases. ${ }^{4-6}$ Other diseases associated with peripheral eosinophilia, such as parasitic infection, vasculitis, lymphoma, carcinoma, or inflammatory bowel disease, however, have to be ruled out. ${ }^{78}$

The aetiology of eosinophilic gastroenterocolitis is unknown. There are controversial reports on abnormal allergic and immunological phenomena. ${ }^{4-11}$

Abnormal eosinophilic infiltration of the bowel wall is defined as at least 20 eosinophils per high power field in most studies. An increase of mucosal IgE containing plasma cells, as in our case (Fig 4), may point to an allergic mechanism and was reported earlier by Lucak et al. ${ }^{12}$

Eosinophilic infiltration of the entire gastrointestinal tract has been described from the oesophagus to the rectum, although most commonly it affects the gastric antrum and the proximal small bowel. ${ }^{413}$ After a review of Klein et al in 1970 the concept has become widely accepted that the infiltrate can predominate in different layers of the bowel wall, with varying clinical symptoms (mucosal, muscular, or subserosal disease) ${ }^{14}$ According to an important study from the Mayo Clinic, only patients with subserosal disease were distinct from other groups in presentation (abdominal bloating, ascites, higher peripheral eosinophil counts) and had a better response to corticosteroids. ${ }^{4}$ In cases with mucosal involvement protein loss and steatorrhoea were described by others. ${ }^{915} 16$

Endoscopy and radiology can be helpful 


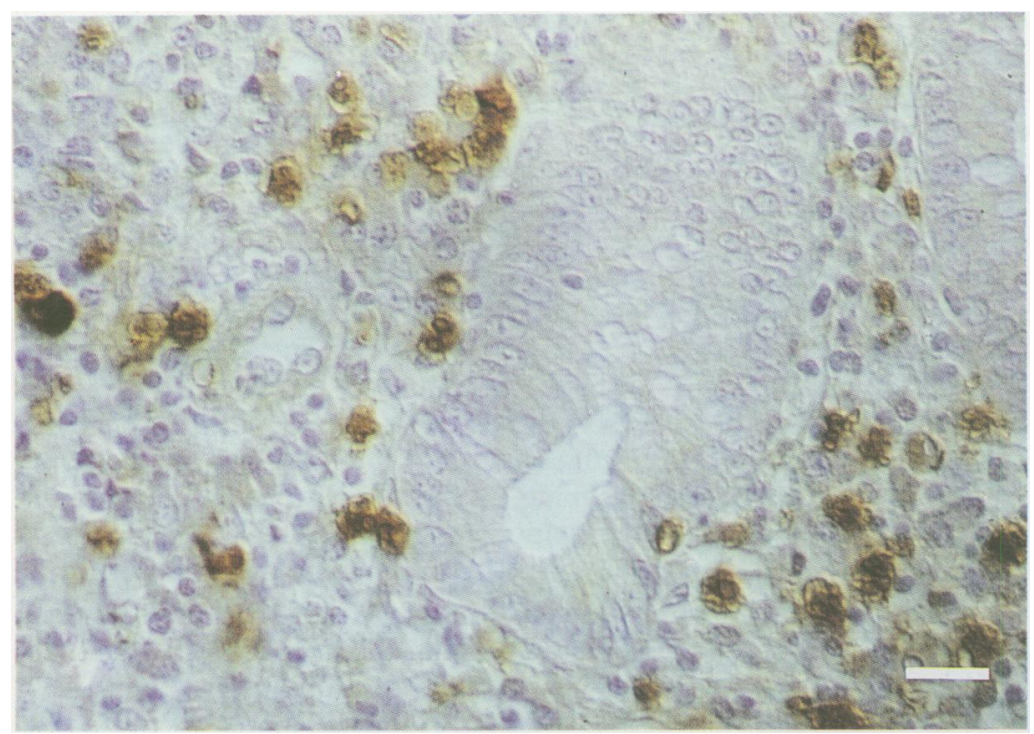

Figure 4: Endoscopic biopsy specimen of the caecum showing an increased number of IgE containing plasma cells, indirect immunoperoxidase staining with diaminobenzidine (bar=approximately 3 micrometer). inflammation, however, the patchy distribution of the disease is well known.

This case is described for two reasons. Firstly, localisation of the site of the intestinal protein loss seemed to be possible with ${ }^{99 \mathrm{~m}} \mathrm{Tc}$ albumin scintigraphy. The procedure is convenient, easy to perform, and can give results within a day. This method has, as far as we know, not been used for the diagnosis of eosinophilic gastroenterocolitis.

A further novelty in this patient is that the unacceptable side effects of conventional corticosteroid treatment could be avoided with budesonide CIR. The effect of budesonide is mainly topical and about $90 \%$ of the drug is metabolised in the liver at its first passage. ${ }^{2}$ There is a strong anti-inflammatory effect but the plasma cortisol concentrations are only slightly depressed so that the usual side effects do not appear. The oral form of budesonide CIR is targeted to be released in the distal ileum and proximal colon and was especially useful in our case with this specific disease localisation.

We would like to thank Astra for supplying budesonide (CIR).

in establishing the diagnosis, especially in mucosal disease. In typical cases a nodular pattern with erosions of the antrum, terminal ileum or colon can be seen at endoscopy. ${ }^{17}$ Radiological abnormalities described in eosinophilic gastroenterocolitis are: stricture; a rigid ileocaecal value open to reflux; filling defects; thickening of the wall; ulceration; and polypoid lesions. $^{7}$

Mucosal disease is detected by the finding of eosinophilic infiltration of biopsy specimens of the gastrointestinal tract. Because of the patchy distribution multiple biopsy specimens from several sites have to be taken, also from normal looking mucosa. Eosinophilic infiltration of the muscular layer mimics intestinal obstruction. Although eosinophils can sometimes be found in mucosal biopsy specimens, the diagnosis is usually made after histological examination of a resection specimen. In most cases of serosal disease, ascites with a high eosinophilic count is found and concurrent eosinophilic pleuritis has been described in this condition. ${ }^{18}$

Corticosteroids are the mainstay of treatment with good symptomatic responses being reported. ${ }^{7814}$ Unfortunately no controlled trials have been performed in this rare disease. Elimination diet seems logical in the case of a strong indication of a specific food allergy, but relapse is common. ${ }^{6}$ Successful treatment with histamine $\mathrm{H}_{1}$ antagonists or mast cell stabilising drugs has been described in a few cases. ${ }^{19} 21-22$

In summary, in our 42 year old female patient, the diagnosis of eosinophilic enterocolitis was not established during a long period of investigations and follow up, as no biopsy specimens were taken from endoscopically normal appearing caecum and terminal ileum. Treatment with budesonide, after the diagnosis was made, resulted in an important improvement of the clinical condition, normalisation of the serum albumin concentration, and reduction of ${ }^{99 \mathrm{~m}} \mathrm{Tc}$ labelled albumin accumulation in the caecum and terminal ileum. Follow up biopsy specimens of these areas showed some improvement of the
1 Divgi CR, Lisann NM, Yeh SD, Benua RS. Technetium$99 \mathrm{~m}$ albumin scintigraphy in the diagnosis of protein losing enteropathy. F Nucl Med 1986; 27 : 1710-2.

2 Brattsand R. Overview of newer glucocorticoid preparates for inflammatory bowel disease. Can $\mathcal{F}$ Gastroenterol 1990; 4: 407-14.

3 Kaijser R. Zur Kenntnis der allergischen Affectionen des Verdauungskanals von Standpunkt des Chirurgen aus. Arch Klin Chir 1937; 188: 36-64.

Talley NJ, Shorter RG, Philips SF, Zinsmeister AR Eosinophilic gastroenteritis: a clinicopathological study of patients with disease of the mucosa, muscle layer, and subserosal tissues. Gut 1990; 31: 54-8.

5 Blackshaw AJ, Levinson DA. Eosinophilic infiltrates of the gastrointestinal tract. $\mathcal{f}$ Clin Pathol 1986; 39: 1-7.

Spry CIF. Eosinophilic gastroenteritis. In: Bouchier IAD Allan RN, Hodgson HJF, et al eds. Textbook gastroenterology. London: Ballière Tindall, 1984: 596-8.

7 Tedesco FJ, Huckaby CB, Hamby-Allen M, Ewing GC Eosinophilic ileocolitis: expanding spectrum of eosinophilic gastroenteritis. Dig Dis Sci 1981; 26: 943-8. Naylor AR, Pollet JE. Eosinophilic colitis. Dis Colon Rectum 1985; 28: 615-8.

9 Cello JP. Eosinophilic gastroenteritis - a complex disease entity. $A m$ F Med 1979; 67: 1097-104.

10 Caldwell JH, Mekhjian HS, Hurtubise PE, Beman FM. Eosinophilic gastroenteritis with obstruction Immunological studies of seven patients. Gastroenterology 1978; 74 825-8.

11 Leinbach GE, Rubin CE. Eosinophilic gastroenteritis: simple reaction to food allergens? Gastroenterology 1970 59: 874-89.

12 Lucak BK, Sansaricq C, Snyderman SE, Greco MA Fazzini EP, Bazaz GR. Disseminated ulcerations in allergic eosinophilic gastroenterocolitis. Am $\mathcal{F}$ Gastroentero 1982; 77: 248-52.

13 Schulze K, Mitros FA. Eosinophilic gastroenteritis nvolving the ileocecal area. Dis Colon Rectum 1979; 22, 47-50.

14 Klein NC, Hargrove RL, Sleisenger MH, Jeffries GH. Eosinophilic gastroenteritis. Medicine 1970, 49: 299-319. Eosinophian A Saverymutu SH, Tai PC, Thompson Barter S, Spry CJ, et al. Activated eosinophils in familial 1041-9.

16 Steffen RM, Wyllie R, Petras RE, Caulfield ME, Michener WM, Firor HV, et al. The spectrum of eosinophilic gastroenteritis: report of six pediatric cases and review of the literature. Clin Pediatr (Phila) 1991; 30: 404-11.

17 Partyka EK, Sanowski RA, Kozarek RA. Colonscopic 1980; 23: 353-6.

18 Marnocha KE, Maglinte DD, Kelvin FM, McCune M, Weiser DC, Strate R. Eosinophilic enteritis associated with chronic eosinophilic pneumonia. Am $\mathcal{f}$ Gastroenterol 1986; 81: $1205-8$.

19 Heatley RV, Harris A, Atkinson M. Treatment of a patient with clinical features of eosinophilic gastroenteritis and polyarteritis nodosa with oral sodium cromoglycate and polyarteritis nodosa with

20 Moots RJ, Prouse P, Gumpel JM. Near fatal eosinophilic P. Gut 1988; 29: 1282-5.

21 Di Gioacchino M, Pizzicannella G, Fini N, Falasca F, Antinucci R, Masci S, et al. Sodium cromoglycate in the treatment of eosinophilic gastroenteritis. Allergy 1990; 45: 161-6.

22 Melamed I, Feanny SJ, Sherman PM, Roifman CM. Benefit of ketotifen in patients with eosinophilic gastroenteritis. Am ₹ Med 1991; 90: 310-4.

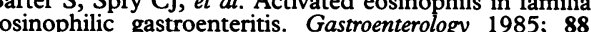
features of eosinophilic gastroenteritis. Dis Colon Rectum 